\title{
The Swim Drink Study
}

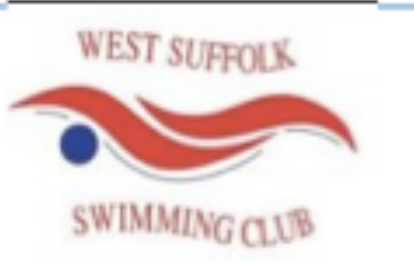

\section{Invitation to participate in a research study measuring swimming performance with different drinking plans}

We invite you to participate in research which we think may be important. The information that follows tells you about this research. It is important that you understand what is in this leaflet. It says what will happen if you take part and what the risks might be. Try to make sure you know what will happen to you if you decide to take part. Whether or not you do take part is entirely your choice. Please ask any questions you want to about the research and we will try our best to answer them.

\section{What we are asking}

We want you to attend your Friday evening training session as usual. We want to weigh you and your water bottle and to ask you how thirsty and how energetic you feel before and after the session. When you weigh in at the session we will let you know whether you should be drinking water, a sports drink (that we will provide) or nothing. You should drink as much or as little as you feel you need during the first 90 minutes of the session. For the final 30 minutes of the session there will be a test set of $10 \mathrm{x} 100 \mathrm{~m}$ freestyle repetitions for you to do and we will time the middle 50metres of this using the electronic timing equipment. We will film the touch pads during the test set so that we have a backup timing method. We plan that you will do this for 12 consecutive Friday training sessions.

Overall we are aiming to recruit $20-40$ swimmers.

\section{What is the purpose of the study?}

Nobody really knows whether drinking when you are training in the pool lets you swim faster. Companies who make sports drinks say that their drinks improve sporting performance, but no-one has published proof of this in swimmers. We want to find out if drinking makes any difference to how fast you can swim.

\section{How will this affect me?}

This will be just like a normal training session and you coach will set the training program as usual. There are no risks to you from this study over and above those that you would be exposed to in your swimming training.

\section{Is this confidential?}

We will record your name as we collect the information. This is just to check we have got it right. Once we have finished analysing the data it will become anonymous. 
What will happen to the results?

The information obtained from our research could be published in scientific journals and discussed at scientific and medical conferences. It would be completely anonymous.

\section{Feedback}

When we have analysed the results we will let you know what we found.

\section{Is this ethical?}

We have gained approval from the Faculty of Medicine and Health Sciences Research Ethics Committee at The University of East Anglia for this project. The Ethics Committee is an independent panel of experts which assess all research projects for safety, ethical acceptability and that protect participant's interests.

\section{What happens if I am not keen or change my mind?}

You are free to decide not to participate or drop out at any time and this will not affect your training in any way.

\section{Any other Questions?}

Any other questions can be addressed by contacting Dr Briars at Norfolk \& Norwich University Hospital NR7 4UH, Tel: 01603287278 / 01603 287174, alternatively you can address your question through the club chairman at Chair@westsuffolkswimming.co.uk.

Thank you for reading this leaflet. Please keep it and a copy of the consent form 


\section{The Swim Drink Study RESEARCH CONSENT}

Two copies of this form should be signed. One given to the parent, and one kept by the researcher

PARTICIPANT DETAILS

Name

DOB

The subject or parent should complete the following part of this sheet himself/herself

\begin{tabular}{|l|l|l|}
\hline Please initial the yes or no box to indicate your answer & Yes & No \\
\hline Have you read the Participant Information Sheet? & & \\
\hline Have you had the opportunity to ask questions and discuss this study? & & \\
\hline Have you received satisfactory answers to all of your questions? & & \\
\hline Have you received enough information about the study? & \\
\hline $\begin{array}{l}\text { Do you understand that swimmers touches at the timing pads will be filmed } \\
\text { to assist in the determination of swim times? }\end{array}$ & & \\
\hline $\begin{array}{l}\text { Do you understand that you are free to withdraw from the study: } \\
\text { at any time: without having to give a reason; without affecting your } \\
\text { training? }\end{array}$ & & \\
\hline \begin{tabular}{l} 
Do you agree to take part in this study? \\
\hline
\end{tabular} & & \\
\hline
\end{tabular}

NAME OF PARENT OR GUARDIAN (in bock letters)

Signed (parent/guardian):

Date:

Signed (swimmer if appropriate)

Date:

NAME OF RESEARCHER SEEKING CONSENT (in bock letters)

Signed:

Date: 


\section{The Swim Drink Study}

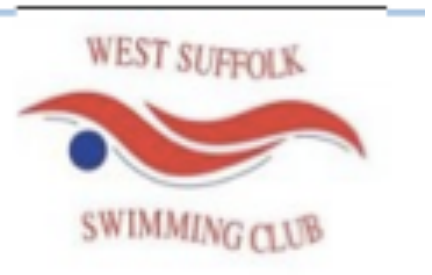

\section{Invitation to participate in a research study measuring swimming performance with different drinking plans}

We invite your child to participate in research which we think may be important. The information that follows tells you about this research. It is important that you understand what is in this leaflet. It says what will happen if they take part and what the risks might be. Try to make sure you know what will happen to you if you decide to allow them take part. Whether or not they do take part is entirely your choice and their choice. Please ask any questions you want to about the research and we will try our best to answer them.

\section{What we are asking}

We want them to attend Friday evening training session as usual. We want to weigh them and their water bottle and to ask them how thirsty and how energetic they feel before and after the session. When they weigh in at the session we will let them know whether they should be drinking water, a sports drink (that we will provide) or nothing. They should drink as much or as little as they feel that they need during the first 90 minutes of the session. For the final 30 minutes of the session there will be a test set of $10 \times 100 \mathrm{~m}$ freestyle repetitions for them to do and we will time the middle 50metres of this using the electronic timing equipment. We will film the touch pads during the test set so that we have a backup timing method in Accordance with FINA rules. We plan that they will do this for 12 consecutive Friday training sessions.

By the end of the study each swimmer will have done 12 test sets. Six of these will follow training sessions where no drink was used, Three will follow training session where sports drinks were drunk and three will have followed session where plain water was drunk. Each swimmer will have their own special random order for what they drink at each session so that nobody can predict what they will be drinking at any particular session. At any particular tpre test raining session there will be swimmers drinking according to a range of different drinking plans. We will only use the times from eight of the sessions for the main study analysis, so that we as the experimenters will not know which sessions will count until all of the data has been collected.

If a swimmer misses a session we may be able to use data from one of the spare sessions, or we may offer a further session.

If a swimmer in a non drinking session feels that they are so thirsty that they really need to drink, they will be allowed to drink water. That session will not be used for the analysis. If there is not a suitable spare session that we can use we may not be able to tell that swimmer which drinking plan had been the best for them.

Overall we are aiming to recruit 20-40 swimmers. 


\section{What is the purpose of the study?}

Nobody really knows whether drinking when you are training in the pool lets you swim faster. Companies who make sports drinks say that their drinks improve sporting performance, but no-one has published proof of this in swimmers. We want to find out if drinking makes any difference to how fast our individual swimmers can swim.

\section{How will this affect me?}

This will be just like a normal training session and the coach will set the training program as usual. There are no risks to the swimmers from this study over and above those that they would be exposed to in their swimming training.

\section{Is this confidential?}

We will record swimmer's names as we collect the information. This is just to check we have got it right. Once we have finished analysing the data it will become anonymous.

\section{What will happen to the results?}

The information obtained from our research could be published in scientific journals and discussed at scientific and medical conferences. It would be completely anonymous.

\section{Feedback}

When we have analysed the results we will let you know what we found.

\section{Is this ethical?}

We have gained approval from the Faculty of Medicine and Health Sciences Research Ethics Committee at The University of East Anglia for this project. The Ethics Committee is an independent panel of experts which assess all research projects for safety, ethical acceptability and that protect participant's interests.

\section{What happens if I am not keen or change my mind?}

You are free to decide not to participate or drop out at any time and this will not affect your child's training in any way.

\section{Any other Questions?}

Any other questions can be addressed by contacting Dr Briars at the address at the top of this Any other questions can be addressed by contacting Dr Briars at Norfolk \& Norwich University Hospital NR7 4UH, Tel: 01603287278 / 01603 287174, alternatively you can address your question through the club chairman at Chair@westsuffolkswimming.co.uk.

\section{Thank you for reading this leaflet. Please keep it and a copy of the consent form}

